\title{
Retraction Note to: Mass barium carbonate poisoning with fatal outcome, lessons learned: a case series
}

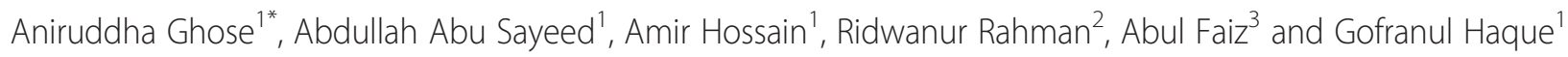

\section{Retraction note}

This article [1] has been retracted by the publisher because it was republished in the journal [2] due to an error during transfer of the journal between publishers in 2009. BioMed Central apologizes to the authors and readers for this error and for any inconvenience caused.

\section{Author details}

${ }^{1}$ Department of Medicine, Chittagong Medical College. ${ }^{2}$ Department of Medicine, Shaheed Suhrawardy Medical College. ${ }^{3}$ Department of Medicine, Sir Salimullah Medical College.

\section{References}

1. Ghose A, Sayeed AA, Hossain A, Rahman R, Faiz A, Haque G. Mass barium carbonate poisoning with fatal outcome, lessons learned: a case series. Cases J. 2009;2:9327.

2. Ghose A, Sayeed AA, Hossain A, Rahman R, Faiz A, Haque G. Mass barium carbonate poisoning with fatal outcome, lessons learned: a case series. Cases J. 2009;2:9069.

\footnotetext{
* Correspondence: anrdghs@yahoo.com 